\title{
GASTRIC MOTILITY AFTER PYLORIC OBSTRUCTION IN INFANCY *
}

\author{
BORDEN S. VEEDER, MALVERN B. CLOPTON \\ AND
}

R. WALTER MILLS

5T. LOUIS

In a ward discussion of pyloric stenosis and pylorospasm in infancy, the question was raised as to the results of operation or nonoperation upon gastric function and motility later on in life. Despite the voluminous literature on the subject of pyloric obstruction from both the medical and surgical standpoints, we were unable to find any data relating to this point, except the statement, which coincided with our own observation, that children who recovered from pyloric stenosiseither with or without operative intervention-seemed to develop normally and to have no ill effects from the early disorder and malnutrition.

In order to obtain some definite data we determined to hunt up some old medical and surgical cases which had been treated in the past at the St. Louis Children's Hospital and make studies of the gastrointestinal motility, and enlisted the services of Dr. Mills of the department of roentgenology to carry out the roentgen-ray examinations. The children were given a barium and milk meal in the morning on an empty stomach and the passage of the meal was watched with the fluoroscope. From time to time roentgenograms were made for permanent record.

It was decided to study two groups of cases-the nonoperated and the operated-for the purpose of comparison. After four cases in each group were studied we found the results were so uniform that it did not seem worth while to enlarge the series and we are presenting the findings in the eight cases in this paper.

\section{REPORT OF CASES}

CASE 1 (47716).-History.-B. S., boy, 4 years of age, was first seen July 16, 1917, when 2 months of age. Weight at this time, $4,330 \mathrm{gm}$. The baby had been breast fed every three hours and when one month of age started to vomit shortly after feedings. The vomiting was projectile in type.

No tumor could be felt. Peristaltic waves were visible. The baby was watched for several days and a diagnosis of pylorospasm was made. As the nutrition was not bad, the baby was placed on atropin and lavage and kept on the breast. There was a slow but steady improvement and the vomiting gradually stopped after a period of several months. The baby was under

\footnotetext{
* Received for publication, July 25, 1922.

* From the Department of Pediatrics, Washington University School of Medicine ard the St. Louis Children's Hospital.
} 
observation for more than a year at an infant welfare center, but had not been seen for two years before the time it was brought back for examination.

Gastro-Intestinal Examination.-The barium meal passed rapidly and in a normal manner through the pylorus. Thirty-five minutes after the meal was given the clearance was active. A roentgenogram taken at four and threequarters hours (Fig. 1) shows a small amount left in the stomach, but nearly all of the meal in the small intestine, cecum and ascending colon. The conditions as to gastric motility are considered as normal.

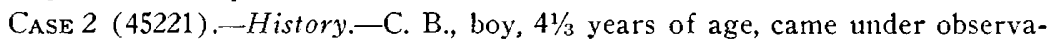
tion in April, 1917, when 5 months of age. At this time the baby was badly undernourished, weighing $3,900 \mathrm{gm}$. He had been fed for two months on the breast and since that time on various milk modifications and proprietary foods in an attempt to check the persistent vomiting which had been present since the second or third week of life. The baby had typical projectile vomiting.

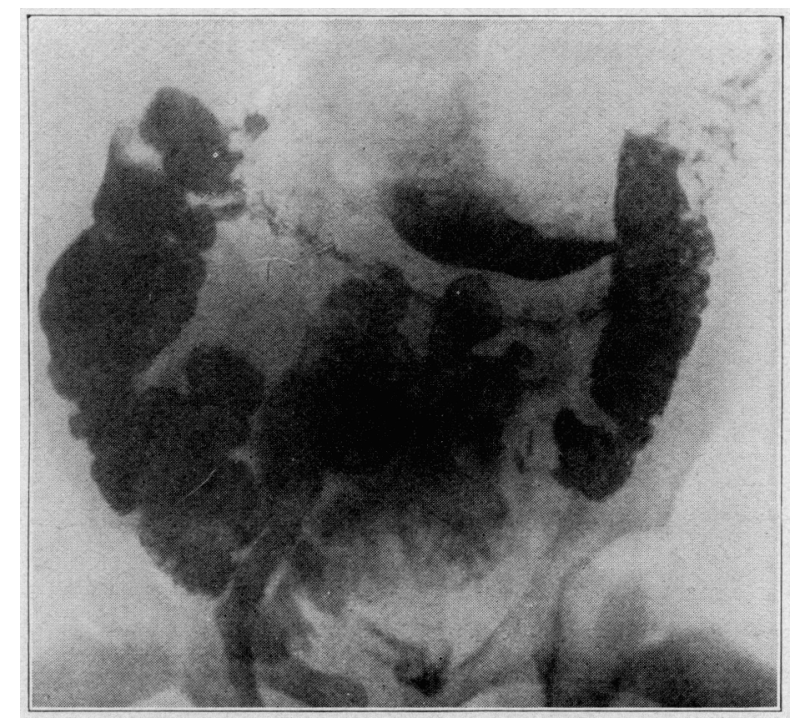

Fig. 1.-Case 1 (no operation), four and three-quarters hours after meal. Small amount still in stomach.

No tumor mass could be felt. Peristaltic waves were present. A diagnosis of pylorospasm was made and atropin (1/\%0 grain) before each feeding was started. The vomiting gradually became less and the general condition of the patient improved slowly but steadily. The balsy was kept under observation and treatment for some time.

Gastro-Intestinal Examination.-Under the fluoroscope the barium and malted milk was observed to pass normally through the stomach. Figure 2, taken immediately after the meal had been given, shows the barium already passing through the pylorus, and Figure 3, taken four and one quarter hours later, shows the stomach empty.

CASE 3 (6038).-History-V. S., boy, 8 years of age was treated in the hospital in November and December, 1913. He was brought to the hospital when 10 weeks of age, weighing $5 \frac{1}{2}$ pounds. $\mathrm{He}$ was said to have weighed $7 \frac{1}{2}$ pounds at birth and then gained about two pounds. Near the end of the first month he started to vomit. The vomiting increased steadily and there was a loss of weight. In the hospital it was noted that visible peristalsis, accompanied hy projectile vomiting, following each feeding. 


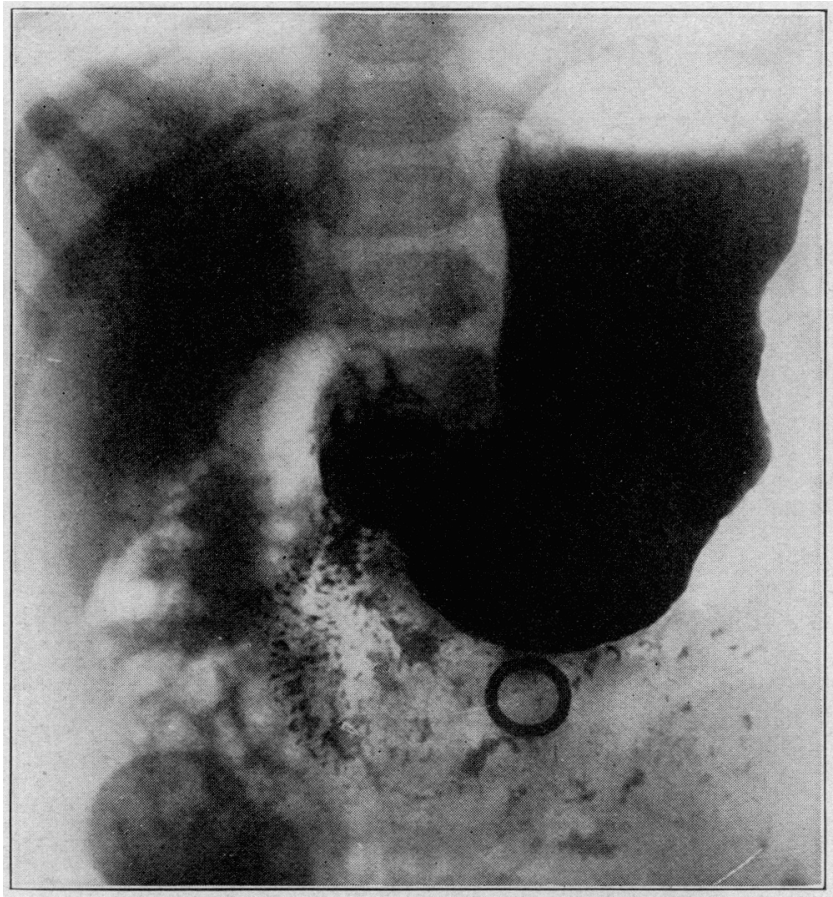

Fig. 2.-Case 2 (no operation), shortly after meal. Shows harium passing through pulorus.

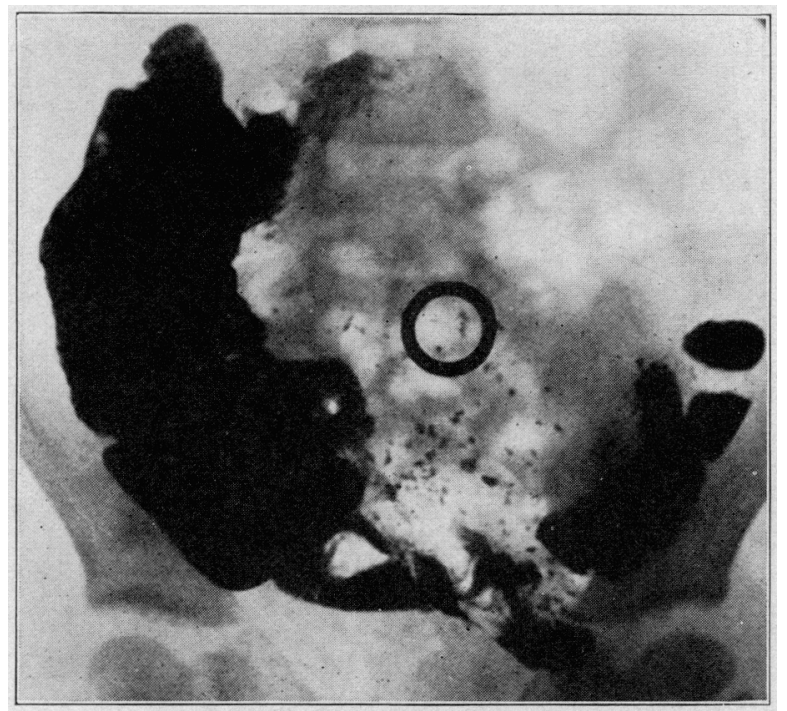

Fig. 3.-Case 2 (no operation), four hours after meal. Stomach empty and harium in small intestine and colon. 
No tumor was palpable. A diagnosis of pylorospasm or pyloric stenosis was made and lavage, together with atropin, before each breast feeding was started. There was gradual, slow and rather irregular improvement, vomiting decreasing and increasing again in turn. After seven weeks of hospital treatment, the baby was cared for in the Outpatient Department. After six months the vomiting stopped and by ten months the baby had reached the normal weight line.

Gastro-Intestinal Examination. - In this case the conditions as to gastric motility were likewise found normal. There was no abnormality in the initial motility and the pylorus was definitely canalized, actively and passively. If anything, the motility must be considered very active, as four hours after the meal was taken the stomach was empty and the barium was in the colon.

CASE 4.-History.-C. B., girl, 6 $1 / 2$ years of age, was a sister of the patient in Case 5. This baby was not treated by us when an infant, but was treated for pyloric stenosis at her home and at another hospital. The history was typical of the condition. The baby was attended by two excellent pediatricians and there is no question as to the diagnosis. She was not operated on, but

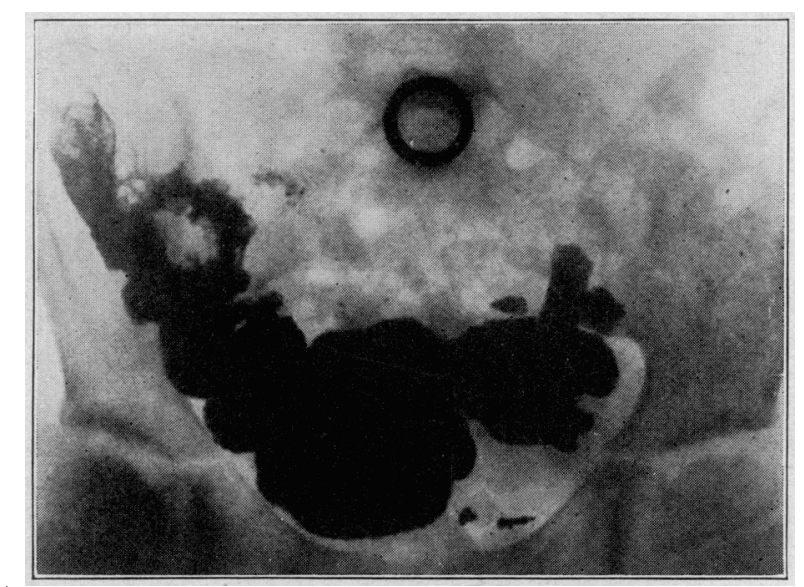

Fig. 4.-Case 4 (no operation), four and one quarter hours after meal. Stomach empty and barium almost entirely in colon.

was treated with lavage and atronin. Two years later another child (Case 5) was born and when 4 weeks of age he developed the same condition. This second baby came into the hospital and was operated on, as reported later. The father very kindly consented to the examination of both children. The nonoperated baby had a very difficult first year. She has never been a strong and healthy child and has about the same physical development as the brother, who is two years younger and who was operated on. This is the only case in our experience in which we have evidence that the malnutrition in infancy, which was severe in this case, seemingly affected the development of the child.

Gastro-Intestinal Examination.-Normal conditions were found as to gastric motility and gastric structural conditions. There was a slight initial pyloric spasm lasting for ten minutes observed under the fluoroscope, but no apparent alnormality in the length or width of the pyloric sphincter. There was no suggestion of gastric dilatation or other abnormality. The duodenal cap and pylorus were perfect in formation. Figure 4, at four and one fourth hours, shows the stomach empty and the barium meal in the small intestine, cecum and ascending colon. 
CASE 5 (11194),-History-C. B., a boy, aged $4 \frac{1}{2}$ years, is the brother of the patient in Case 4 . He was breast fed. When 4 weeks of age he developed typical pyloric obstruction with projectile vomiting, starvation stools and visible peristalsis. He was sent to the hospital and failed to improve on routine medical treatment. He was then operated on by Dr. Clopton, who found a thick, olive shaped pyloric tumor with a greatly enlarged stomach. The muscle was incised by the Rammstedt method and measured $7 \mathrm{~mm}$. in thickness. The vomiting stopped after the operation and the child made a good recovery and gained weight rapidly.

Gastro-Intestinal Examination.-Normal conditions were found as to gastric motility and structural conditions. There was no suggestion of gastric dilatation or other abnormality. The pylorus and cap formation were perfect, and under the fluoroscope no abnormality in the length or width of the pyloric sphincter was found. At the end of four and a half hours there was a very

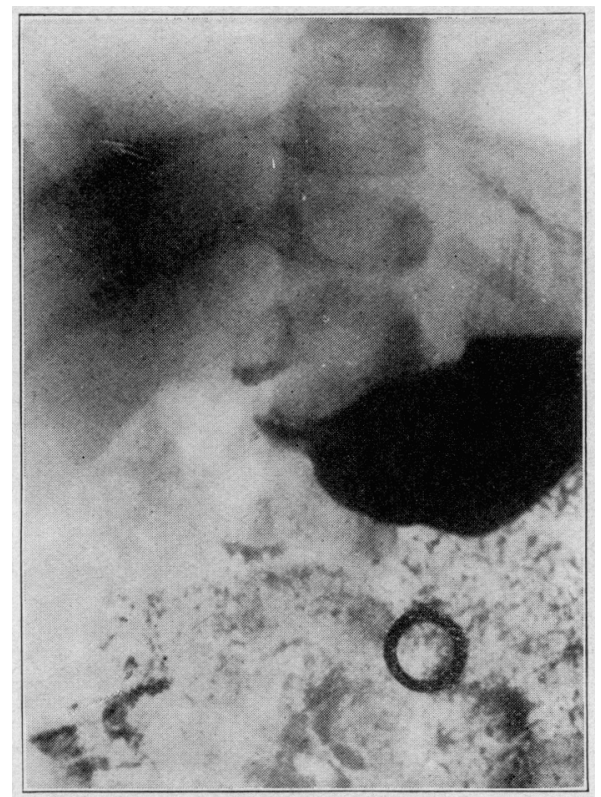

Fig. 5.-Case 7 (operation), shortly after meal. Barium passing through pylorus.

slight amount of the barium meal left in the stomach, but nearly all had passed into the small intestine, cecum and ascending colon.

Case 6 (15188).-History--J. T., male, 15 months of age, was admitted to the hospital in February, 1920, when one month of age. Birth was normal. When about two weeks old, the baby started to vomit and nearly all of the feedings were regurgitated. On examination visible peristalsis and a palpable tumor were found. The baby failed to respond to medical treatment and ten days after admission was operated on. A moderate size tumor was found which was incised according to the Rammstedt method. The baby stopped vomiting the day following the operation and did not vomit again while in the hospital. The baby started to gain weight rapidly and at the end of the first year the weight was normal. This baby has been under constant observation and has never shown the slightest abnormality in gastr:c function since the operation. 


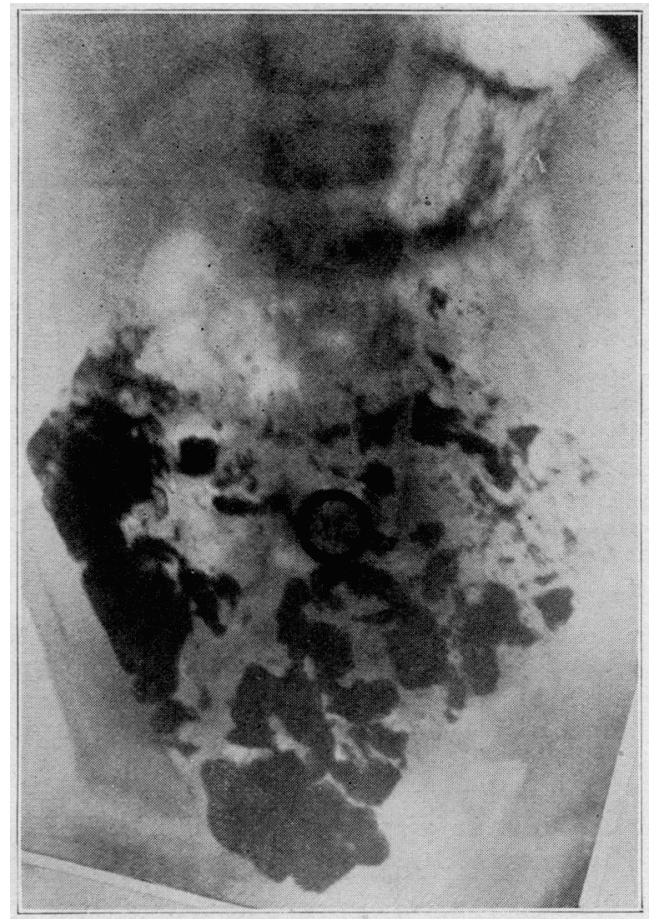

Fig. 6.-Case 7 (operation), four hours after meal. Stomach empty.

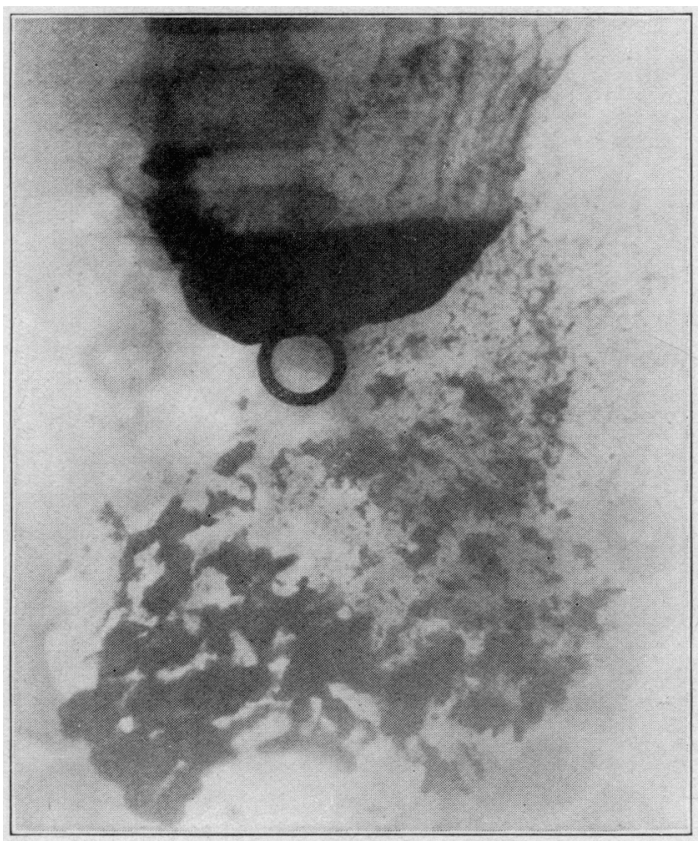

Fig. 7.-Case 8 (operation), shortly after meal. Shows harium passing through pylorus. 
Gastric-Intestinal Examination.-On roentgen-ray examination there was no apparent abnormality in the motility with the possible exception of a slight retardation in total motility, as at the end of four and three fourths hours a moderate amount of the barium meal was still in the stomach. The initial motility was normal and the pylorus was definitely canalized. No abnormality was apparent in the width of the pyloric sphincter.

CASE 7 (11416).-History'-A. S., girl, 4 years of age, was admitted to the hospital in April, 1917, when 5 weeks of age. She had been breast fed for three weeks. One week after birth vomiting was said to have started. Because of the vomiting the food was changed to an artificial mixture. When brought to the hospital the baby was in bad condition, weighing $3,450 \mathrm{gm}$. Vomiting was projectile in type; peristaltic waves were present and a tumor mass palpable. Because of the malnutrition, the baby was operated on the day following admission and a large pyloric tumor was found, measuring $1.5 \mathrm{~cm}$. in diameter. The stomach was markedly distended. Vomiting stopped following operation and the baby's condition gradually improved until in a few months the condition of nutrition was normal.

Gastro-Intestinal Examination.-The pylorus was observed to function normally under the fluoroscope, canalization taking place, cap and pyloric formation being perfect. Four hours after the meal was taken, the stomach was practically empty and the barium had passed into the small intestine, cecum and ascending colon. Two pictures of this case are shown, Figure 5, taken shortly after meal was given and showing the pylorus; and another, Figure 6, taken four hours later, showing the meal in the small intestine. Conditions as to gastric motility are considered normal.

CASE 8 (9615).-History.-Z. B., boy, 5 years of age, was admitted to the hospital in December, 1915, when 2 months of age. When 3 weeks of age the baby started to vomit and this continued until time of admission. When brought to the hospital the baby was very badly nourished, weighing $3,600 \mathrm{gm}$., peristaltic waves were present and stools were of the starvation type, but no tumor could be feit. The child was treated medically for three weeks. At first it started to improve, but then started to lose weight and so three weeks after admission was operated on. A typical hard cartilaginous tumor was found, $2 \mathrm{~cm}$. in diameter. This was incised. Following the operation vomiting decreased gradually and in about two weeks the baby started to gain. The child was followed through the outpatient department and in a few months all signs of malnutrition had disappeared.

Gastro-Intestinal Examination.-Under the fluoroscope the pylorus was found to function normally. The pyloric sphincter did not appear thicker than normal and the cap and pyloric formation was perfect. The total gastric motility was normal, the stomach being empty after four hours. Figure 7 was taken shortly after the meal was given and gives a very clear picture of the barium meal passing through the pylorus and a small amount in the small intestine.

\section{DISCLSSICN}

The gastric motility of eight children, all of whom had been patients with pyloric obstruction in early infancy, was studied and in every instance was found normal. Four of these, aged 4, 41/3, 6 and 8 years, respectively, had been treated medically, and in four cases, aged $11 / 3,4$, $41 / 2$ and 5 years, respectively, a pyloroplasty (Rammstedt operation) had been done. In the latter four cases a definite tumor was found, but as to whether the obstruction was due to tumor or simple spasm in the four medically treated cases is, of course, uncertain and therefore 
we have classified them as pylorospasm. In each one of these cases persistent vomiting of a projectile type, small stools, visible peristalsis, and malnutrition were present.

At the time of the gastric examination the chi'dren were all in a good conclition of nutrition and with one exception (Case 4) they had developed normally after overcoming the trouble in early infancy. All belonged to the "sthenic" type of habitus, as classified by Mills. ${ }^{1}$

There is little data in regard to gastric motility in children. In the "sthenic" type of habitus in adults the stomach usually empties in from four to five hours, the average time in round numbers in this type, as determined by Mills ${ }^{2}$ in a series of 481 cases, being four hours and forty-five minutes. Interestingly, in asthenic adults complete gastric motility was found by the same author definitely slower, the average time of such total emptying being five hours and forty-five minutes in 118 cases. It would be very interesting if comparable figures of the time of complete gastric motility in different types of children were available. Figures of this sort are a necessity if such time varies anything like what it does in adults. In adults, as determined by Mills, the intermediate hyposthenic type of habitus has a total motility of five hours and thirty minutes as found in a series of 354 subjects and the extreme hypersthenic type, persons of massive physique, high stomachs, and rapid general alimentary motility, has the most rapid gastric motility, four hours and fifteen minutes in a series of forty-seven cases. A factor also to be taken into consideration in studies of complete gastric motility in different types, certainly in adults and also in children by inference, is the incidence of the various types of physique. If one or two intermediate types are, as is actually the case, numerically in marked preponderance as are the sthenic and hyposthenic, the time of complete gastric motility in these types should be consiclered the average or "normal" time, and those of the less frequently occurring hypersthenic and asthenic types as exceptions; yet whose motility time is to be judged by that of similar persons. Figures as to the incidence of types also compiled by Mills from observations on 1,000 adults without known organic or marked functional disturbances are as follows: Hypersthenic habitus, forty-seven, 4.7 per cent.; sthenic habitus, 481 , 48.1 per cent.; hyposthenic habitus, 354, 35.4 per cent., and asthenic habitus, 118, 11.8 per cent. ${ }^{3}$ Recently Sauer, Minsk and Alexander ${ }^{4}$

1. Mills, R. W.: Am. J. Roentgenology 4:155 (April) 1917.

2. Mills, R. W.: Tr. Am. Gastro-enterological Assoc. 36:47, 1918.

3. As an aside, the variation in the incidence of different types of habitus should be taken into consideration in many other conditions, such as the relative occurrence of different diseases in different types; for example, tuberculosis, as occurring in asthenics. Since the asthenic type is comparatively rare, tuberculosis is very much more predilected in such type than is apparent at first sight.

4. Sauer, Minsk and Alexander: J. A. M. A. 79:184 (July 19) 1922. 
reported considerable slowing of the gastric motility in children with anorexia, and for comparison cite the cases of twelve children with good appetite of the "sthenic" habitus. In these children the stomach was empty in one instance by three and one-half hours; in four by four hours; in two by four and one-half hours, and in the remaining five by five hours. In five of our cases the stomach was empty by four and one-half hours or less and in the remaining three cases only a very slight amount was left by this time. Our figures, therefore, fall well within the limits of what may be considered as normal gastric motility. In children of hyposthenic or asthenic habitus the stomach frequently is not emptied before six or seven hours after the meal is given.

It was of particular interest to find that there was no difference between the cases of pyloric obstruction treated medically and those treated surgically. This was the original point raised and our findings lead us to conclucle that the late or end-results cannot be taken into consideration in a given case of pyloric obstruction in infancy, in deciding for or against operation.

\section{CONCLUSIONS}

The gastric motility was studied in eight children from $1 \frac{1}{2}$ to 8 years of age, who had been treated for pyloric obstruction in early infancy. Four had been treated medically and four surgically (Rammstedt operation). In every instance conditions as to gastric motility were found normal. 